\title{
Pseudomyxoma Peritonei Occurring after an Uneventful 23 Years Interval from Appendectomy
}

\author{
Atsuko Taii, Junichi Sakagami, Misumi Shinoda, Hiroya Taniguchi, Masatoshi Tosa, \\ Takehiko Baba, Tomoko Motoyoshi, Reiko Ito, Shoji Mitsufuji, \\ Keisho Kataoka and Takeshi Okanoue
}

\begin{abstract}
A 77-year-old male was admitted to our hospital for a bulky abdominal mass. He had a history of appendectomy under the diagnosis of appendiceal rupture 23 years previously. He also had received a radical lung resection for an early lung cancer 2 years earlier in another hospital. Tentative diagnosis of peritoneal metastases from the lung cancer was made. He then received 3 courses of chemotherapy, but failed to reach a remission. The final diagnosis of pseudomyxoma peritonei was made by means of abdominocentesis, and he underwent debulking surgery. However, he died on day 56 after the surgery. Pseudomyxoma peritonei requires careful observation, as it has the possibility to be detected after a long-term follow-up period of more than 20 years.
\end{abstract}

Key words: pseudomyxoma peritonei, appendectomy

(DOI: 10.2169/internalmedicine.46.0079)

\section{Introduction}

Pseudomyxoma peritonei (PMP) is a rare condition characterized by a large amount of mucinous ascites in the abdominal cavity. PMP most commonly arises from a mucinproducing appendiceal tumor. The neoplasm grows slowly because of its low-grade malignant potential. Reduction surgery is the first-line treatment, but complete resection fails in most cases. We report a case of PMP which developed from mucinous adenocarcinoma in a patient who had undergone an appendectomy 23 years previously. To the best of our knowledge, the current case had the second longest interval before the development of PMP was first noticed after the appendectomy.

\section{Case Report}

A 77-year-old male visited our hospital in September 2004 with the complaint of abdominal fullness. He had undergone a radical lobectomy for early lung cancer (T2, N0, M0, IB) 2 years before in a hospital. He also had a history of appendectomy for ruptured appendicitis as far back as 23 years. Tentative diagnosis of metachronous peritoneal metastases from the lung cancer was made. He then received 3 courses of chemotherapy (CBDCA+PTX) for 5 months but failed to reach a remission. The result was $\mathrm{NC}$ (no change) or PD (progressive disease). The patient came to our hospital for a second opinion concerning his disease.

His abdomen showed marked generalized distention, stony hard, and accompanied with diffuse abdominal pain and tenderness. Bowel sounds were moderate in activity. Laboratory testing showed elevated serum concentrations of CEA and CA19-9 (Table 1). Abdominal ultrasonography revealed a moderate amount of ascites including homogenous clusters (Fig. 1). We performed an abdominocentesis under ultrasound guidance. The aspirate contained a large amount of red jelly-like mucus. Cylindrical epithelial cells with scanty atypia were seen in the mucinous ascites. The cytology was compatible with PMP. Computed tomography (CT) showed that the liver was surrounded by ascites. The mucinous material was similar to fat in density (Fig. 2). T2weighted magnetic resonance imaging (MRI) provided much clearer contrast inside the ascites compared to CT (Fig. 3). 
Chest CT did not reveal any tumors in the lung. We checked a histologic specimen from the early lung cancer resected 2 years earlier. It showed papillary type adenocarcinoma without mucin. We ruled out the possibility of recurrent lung cancer. Gastroendoscopy showed a compressed stomach and a duodenal adenoma. Biopsy of the adenoma did not demonstrate malignancy but showed evidence of severe atypia. We diagnosed his disease as PMP and he underwent debulking surgery. The tumor involved almost all of the visceral organs including the stomach, liver, spleen, small intestine, and colon. Those organs were organized into a large mass, and the stump of the appendix could not be distinguished from other organs. Only about one fifth of the tumor was removed. Mucinous lakes with fibrous stroma were seen in the surgical specimen. Tumor cells with scant atypia lined the mucin lakes. Those findings were compatible with PMP. His postoperative course was not favorable because of a perforation of the small intestine during the surgery. The pa-

Table 1. Laboratory Findings on Admission

\begin{tabular}{lc}
\hline White blood cell & $4200 / \mu l$ \\
Red blood cell & $372 \times 10^{4} / \mu \mathrm{l}$ \\
Hemoglobin & $9.2 \mathrm{~g} / \mathrm{dl}$ \\
Hematocrit & $30.3 \%$ \\
Platelet & $21.3 \times 10^{4} / \mu \mathrm{I}$ \\
& \\
Prothrombin time & $12.5 \mathrm{sec}$ \\
Activated partial thromboplastin time & $36.6 \mathrm{sec}$ \\
Fibrinogen & $504 \mathrm{mg} / \mathrm{dl}$ \\
& \\
Total protein & $6.1 \mathrm{~g} / \mathrm{dl}$ \\
Aspartate aminotransferase & $33 \mathrm{U} / /$ \\
Alanin aminotransferase & $20 \mathrm{U} / \mathrm{I}$ \\
Lactatedehydrogenase & $181 \mathrm{IU} / \mathrm{I}$ \\
Alkaline phosphatase & $331 \mathrm{IU} / \mathrm{I}$ \\
$\gamma-$ Glutamyltranspeptide & $42 \mathrm{IU} / \mathrm{I}$ \\
Total birilubin & $0.6 \mathrm{mg} / \mathrm{dl}$ \\
Blood urea nitrogen & $13.1 \mathrm{mg} / \mathrm{dl}$ \\
Creatinine & $0.62 \mathrm{mg} / \mathrm{dl}$ \\
Sodium & $143 \mathrm{mEq} / \mathrm{l}$ \\
Potassium & $5 \mathrm{mEq} / \mathrm{l}$ \\
Chlorine & $106 \mathrm{mEq} / \mathrm{l}$ \\
C-reactive protein & $10.3 \mathrm{mg} / \mathrm{dl}$ \\
& \\
CEA & $62 \mathrm{ng} / \mathrm{ml}$ \\
CA 19-9 & $7735 \mathrm{U} / \mathrm{ml}$ \\
\hline
\end{tabular}
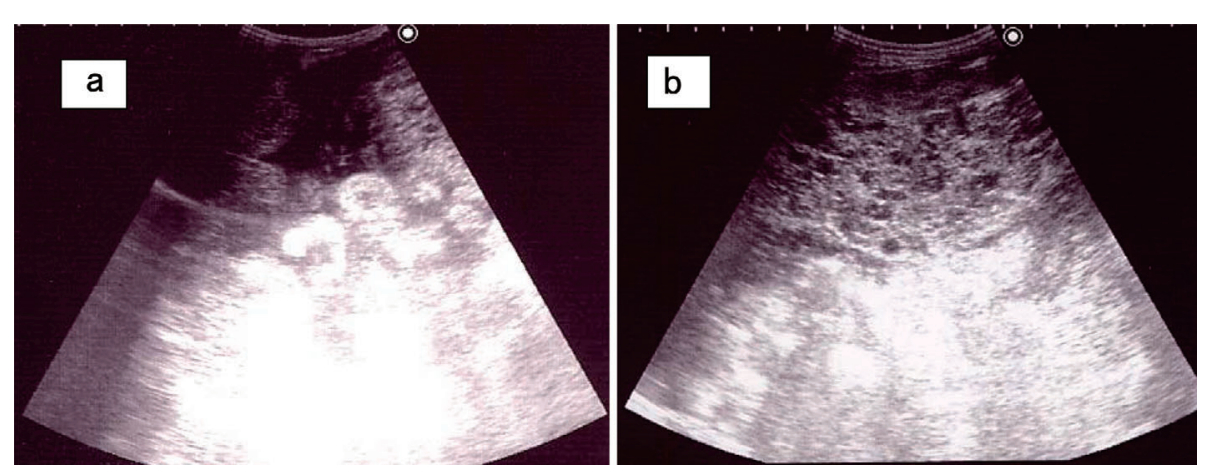

Figure 1. Abdominal ultrasonography revealing a moderate amount of ascites including homogenous clusters. a. Longitudinal plane. $b$. Transverse plane. tient died on day 56 after the surgery due to complications of the operation.

\section{Discussion}

Werth first coined the term of "PMP" in 1884 (1). In 1901, Frankel described a case of a cyst in the appendix complicated by PMP (2). The mean patient age for identification of PMP has been estimated to be 58 years of age (3). According to the cases reported to date, PMP predominantly affects women (4). PMP consists of neoplastic mucinproducing cells in the peritoneal cavity. Mucin usually is secreted from ruptured mucinous neoplasms. Recent morphologic, immunohistochemical, and molecular genetic studies have suggested that the appendix is the most likely primary site of PMP (5-11), which sometimes involves other visceral organs. The colon, uterus, common bile duct, pancreas, and stomach have been documented as rare sites of PMP origin (12). Colonoscopy could not be performed in the present case due to the presence of excessive ascites. Gastroendoscopy did not reveal any malignant tumors in the stomach. CT of the abdomen did not reveal any masses in the common bile duct or pancreas. Though we tried to trace the surgical findings and the pathologic report on the patient's appendectomy in vain, the PMP in our patient seems to have originated from the perforated appendix 23 years

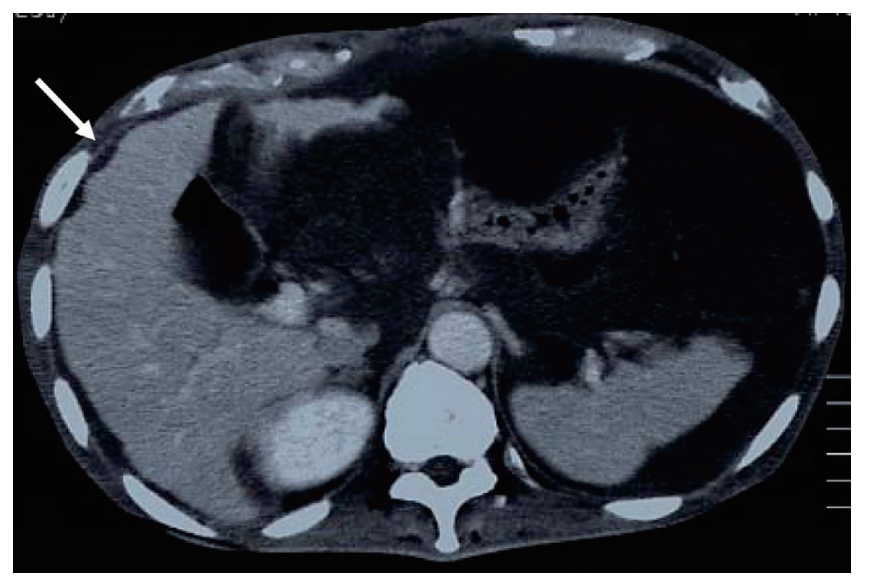

Figure 2. Computed tomographic scan of the abdomen. The arrow indicates the scalloping of the liver. 

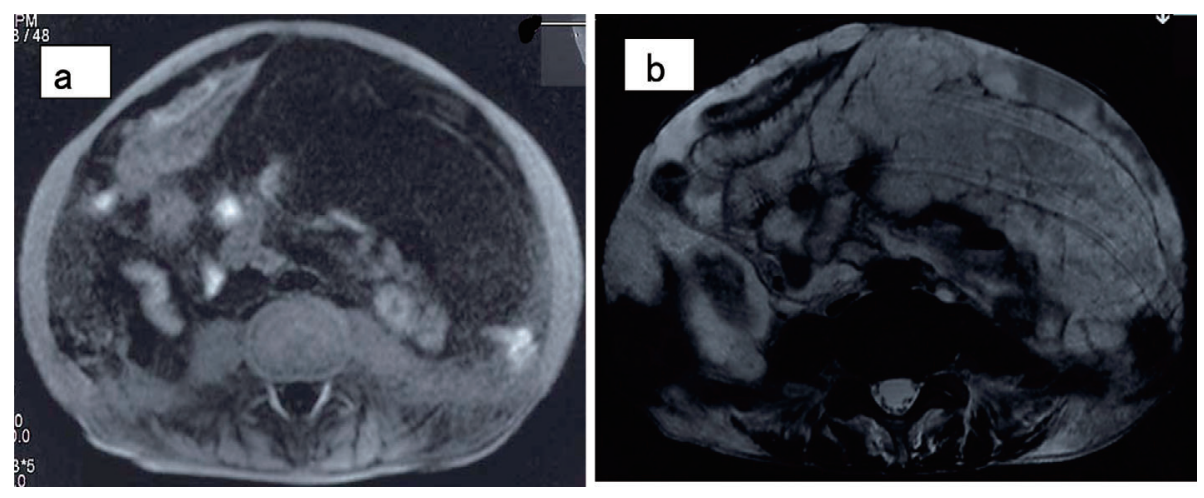

Figure 3. Magnetic resonance imaging. a. T1-weighted image. b. T2-weighted image.

earlier.

Recently Ronnett et al (13) suggested that PMP should be classified into the following 3 types: disseminated peritoneal adenomucinosis (DPAM), peritoneal mucinous carcinomatosis with intermediate or discordant features (PMCA-I/D), and peritoneal mucinous carcinomatosis (PMCA). Of the 109 cases of PMP, DPAM, PMCA-I/D, and PMCA accounted for $59.7 \%, 27.5 \%$, and $12.8 \%$, respectively. They reported 5-year survival rates as $75 \%$ for DPAM, 50\% for PMCA-I/D, and $14 \%$ for PMCA. The present patient is classified as DPAM. In the study by Ronnett et al (13), all patients were treated with cytoreduction surgery, followed by systemic and intraperitoneal chemotherapy. They also documented that the prognosis could be predicted based on the appearance of the peritoneal lesion alone without any information about the origin.

Though CEA and CA19-9 concentrations have not been measured in many cases, these serum markers have occasionally been found to be elevated (14). High serum concentrations of CEA suggest a poor prognosis and possible re- currence of the disease (15). In the present case, both the levels of CEA and CA19-9 were high.

Surgical debulking is recommended as the first-line therapy (3); chemotherapy is less effective (16). Some have reported the use of 5-fluorouracil, cyclophosphamide, Lphenylalanine mustard, doxorubicin, and cisplatinum (15). But most studies have demonstrated very little improvement in the disease (15). The present patient did not receive any of these chemotherapy regimens. Sugarbaker (17) demonstrated good results of aggressive cytoreduction in 69 PMP patients. Cytoreduction combined with intraperitoneal chemotherapy had 5-year survival rates of minimum, moderate, or gross residual disease at $92 \%, 48 \%$, and $20 \%$, respectively. Patients with PMCA are likely to be responsive to chemotherapy because of their high mitotic activity (13).

There have been a few cases of PMP occurring several years after the removal of a primary lesion $(18,19)$. PMP requires careful observation, as it has the possibility to be detected after a long-term follow-up period of more than 20 years.

\section{References}

1. Werth R. Klinische und Anatomische Untersuchungen zur Lehre von den Bauchgeschwullsten und der Laparotomie. Arch Gynecol Obstet 24: 100-118, 1884 (in German).

2. Frankel E. Uber das sogenannte pseudomyxoma peritonei. Med Wochenschr 48: 965-970, 1901.

3. Mann WJ, Wagner J, Chumas J, Chalas E. The management of pseudomyxoma peritonei. Cancer 66: 1636-1640, 1990.

4. Harshen R, Jyothirmayi R, Mithal N. Pseudomyxoma peritonei. Clin Oncol 15: 73-77, 2002.

5. Ronnett BM, Kurman RJ, Zahn CM, et al. Pseudomyxoma peritonei in women: a clinicopathologic analysis of 30 cases with emphasis on site of origin, prognosis, and relationship to ovarian mucinous tumors of low malignant potential. Hum Pathol 26: 509524, 1995.

6. Young RH, Gilks CB, Scully RE. Mucinous tumors of the appendix associated with mucinous tumors of the ovary and pseudomyxoma peritonei. A clinicopathological analysis of 22 cases supporting an origin in the appendix. Am J Surg 15: 415-429, 1991.

7. Prayson RA, Hart WR, Petras RE. Pseudomyxoma peritonei. A clinicopathologic study of 19 cases with emphasis on site of origin and nature of associated ovarian tumors. Am J Surg Pathol 18: 591-603, 1994.
8. Ronnett BM, Shmookler BM, Diener-West M, Sugarbaker PH, Kurman RJ. Immunohistochemical evidence supporting the appendiceal origin of pseudomyxoma peritonei in women. Int J Gynecol Pathol 16: 1-9, 1997.

9. Cuatrecasas M, Matias-Guiu X, Prat J. Synchronous mucinous tumors of the appendix and the ovary associated with pseudomyxoma peritonei. Am J Surg Pathol 20: 739-746, 1996.

10. Guerrieri C, Franlund B, Fristedt S, Gillooley JF, Boeryd B. Mucinous tumors of the vermiform appendix and ovary, and pseudomyxoma peritonei: histogenetic implications of cytokeratin $7 \mathrm{ex}-$ pression. Hum Pathol 28: 1039-1045, 1997.

11. Szych C, Staebler A, Connolly DC, Wu R, Cho KR, Ronnett BM. Molecular genetic evidence supporting the clonality and appendiceal origin of pseudomyxoma peritonei in women. Am J Pathol 154: 1849-1855, 1999.

12. Higa E, Rosai J, Pizzimbono CA, Wise L. Mucinous cystadenocarcinoma of the appendix. a re-evaluation of appendiceal 'mucocoele'. Cancer 33: 1525-1541, 1973.

13. Ronnett BM, Yan H, Kurman RJ, Shmookler BM, Wu L, Sugarbaker PH. Patients with pseudomyxoma peritonei associated with disseminated peritoneal adenomucinosis have a significantly more favorable prognosis than patients with peritoneal mucinous carci- 
DOI: $10.2169 /$ internalmedicine.46.0079

nomatosis. Cancer 92: 85-91, 2001.

14. Hinson FL, Ambrose NS. Pseudomyxoma peritonei. Br J Surg 85: 1332-1339, 1998.

15. Gough DB, Donohue JH, Schutt AJ, et al. Pseudomyxoma peritonei. Long-term patients survival with an aggressive regional approach. Ann Surg 219: 112-119, 1994.

16. Fukasawa H, Okamoto $M$, Narushima $M$, Nakamura K. Four cases of pseudomyxoma peritonei. Sanka to Fujinka 6: 1027-1033, 1986 (in Japanese).
17. Sugarbaker PH. Cytoreductive surgery and porioperative intraperitoneal chemotherapy as a curative approach to pseudomyxoma peritonei syndrome. Eur J Surg Oncol 27: 239-243, 2001.

18. Miner TJ, Shia J, Jaques DP, Klimstra DS, Brennan MF, Goit DG. Long-term survival following treatment of pseudomyxoma peritonei. Ann Surg 241: 300-308, 2005.

19. van Ruth S, Acherman YI, van de Vijver MJ, Hart AA, Verwaal VJ, Zoetmulder FA. Pseudomyxoma peritonei: a review of 62 cases. Eur J Surg Oncol 29: 682-688, 2003.

(C) 2007 The Japanese Society of Internal Medicine http://www.naika.or.jp/imindex.html 